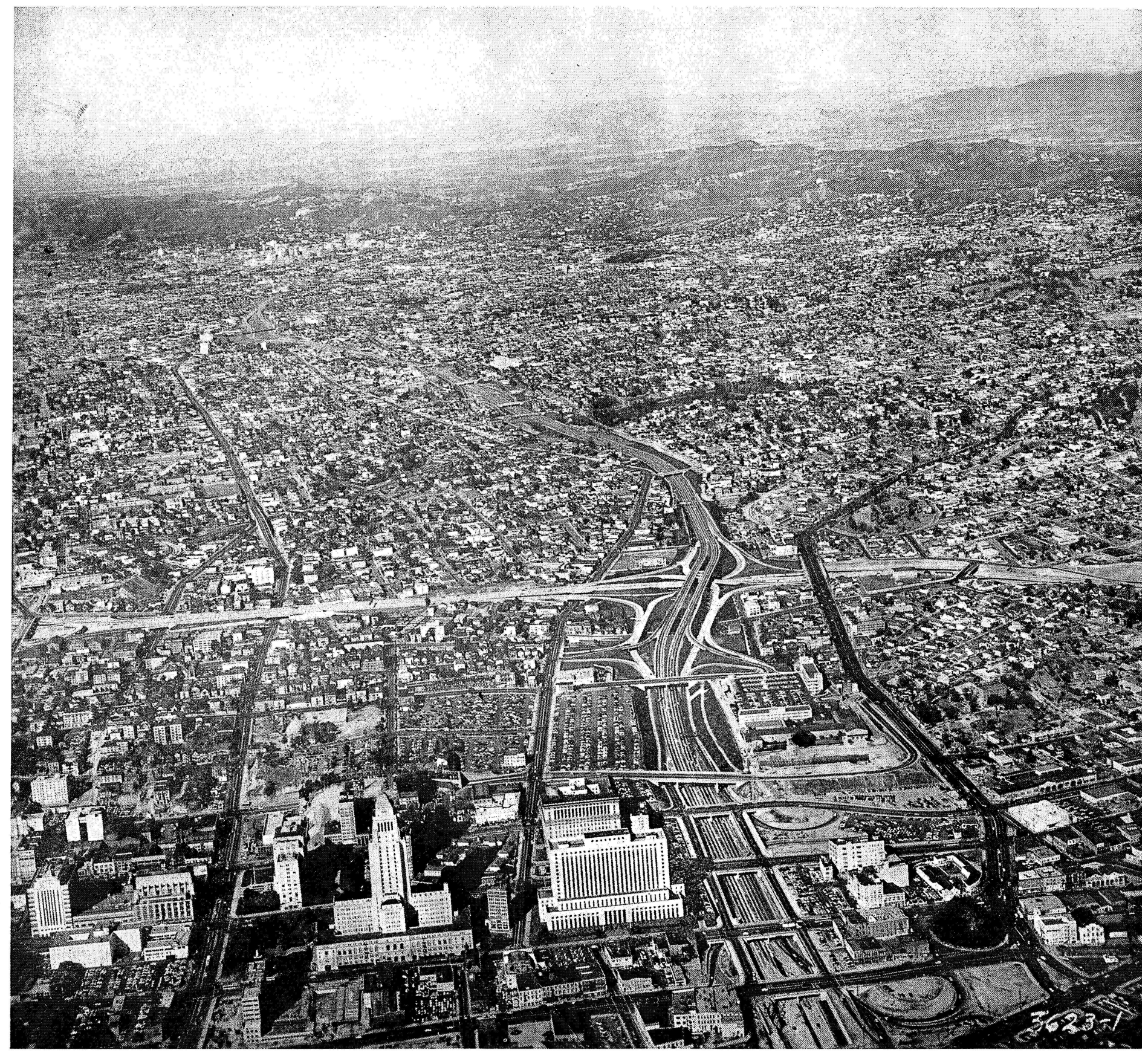

$513 \cdot 7$

\title{
autopistas de California
}

Documentación amablemente facilitada por el "Department

of City Planning" de los Angeles (California)

El extraordinario crecimiento de la circulación rodada en los últimos años y su acusado ritmo ascendente, fácilmente previsible para el futuro, obliga a pensar muy seriamente en el problema que entraña el movimiento de grandes cantidades de vehículos que, por añadidura, y a causa del dinamismo de la vida actual, necesitan marchar de prisa.

INSTITUTO TECNICO DE LA CONSTRUCCION Y DEL CEMENTO 


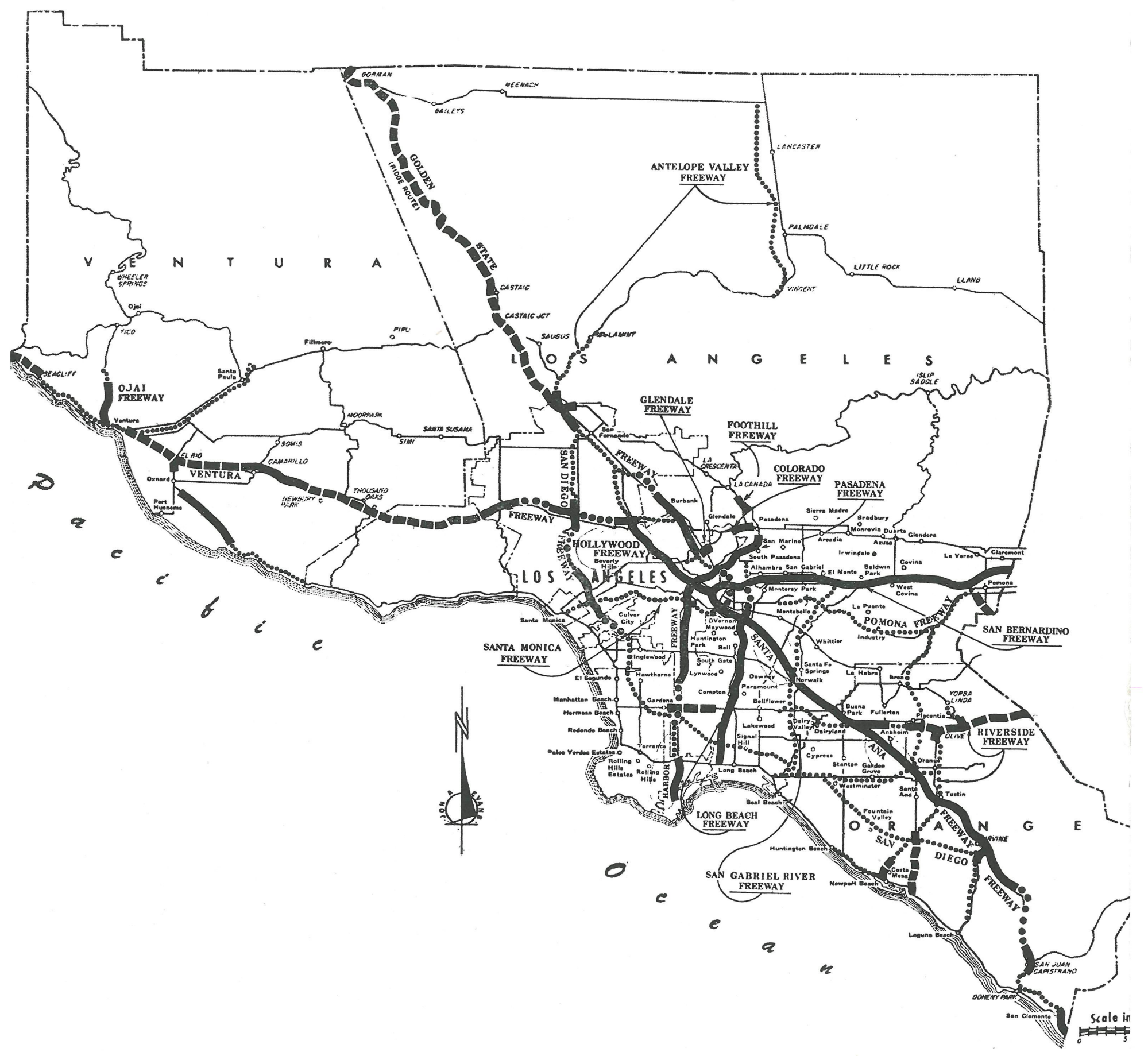

La anchura de las pistas y los cruces a nivel son dos premisas fundamentales que hay que considerar: la primera ha de ser suficiente, y los segundos han de desaparecer. En las autopistas quedan proscritos los cruces a nivel. El tráfico en las dos direcciones debe permanecer expedito, formándose las entradas y salidas por bandas de circulación unidas a las de las autopistas con ángulos muy agudos y de suficiente longitud para que los vehículos puedan acelerar o aminorar, acomodándose a la básica de la autopista.

Por otra parte, las autopistas están construídas fundamentalmente para el recorrido de grandes longitudes $\mathrm{y}$, de aquí, la necesidad de procurar enlaces frecuentes con la red de carreteras que, en zonas muy pobladas, pueden llegar a situarse cada ocho kilómetros. 


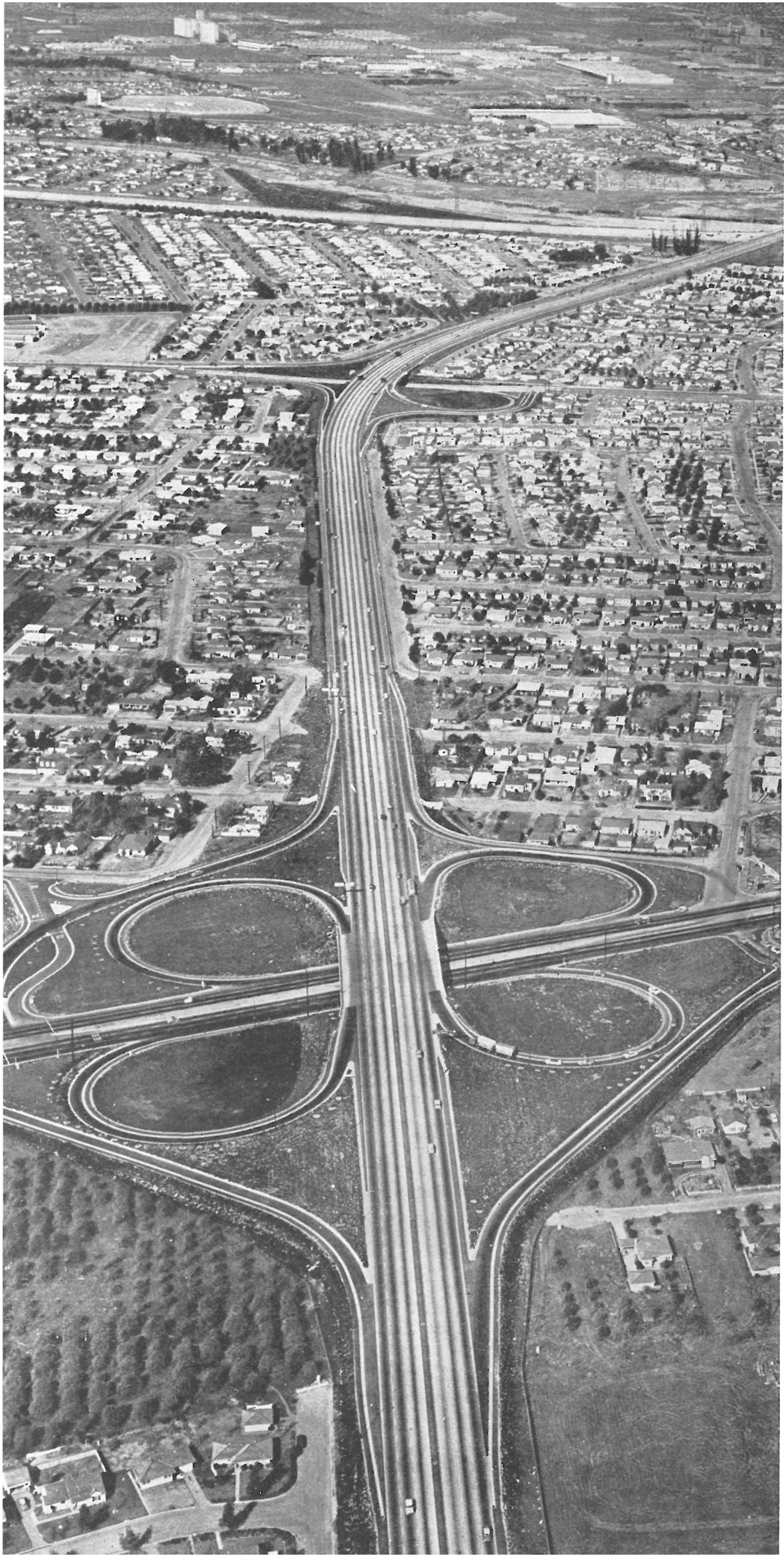

Este artículo se refiere, concretamente, al plan general de autopistas en el distrito VII de California, formado por tres condados: Los Angeles, Orange y Ventura. Los problemas de tráfico pueden dividirse en dos categorías principales: una que se refiere a la zona de Los Angeles y gran parte del condado de Orange; la otra, que comprende el condado de Ventura, el norte del condado de Los Angeles y la banda oriental de Orange.

El tráfico fundamental va de noroeste a sureste, sensiblemente paralelo a la costa del Pacífico, aunque también la dirección este-oeste tiene gran movimiento. El núcleo metropolitano de Los Angeles y su relación con los centros industriales da lugar a una actividad constante y acentuada, que crece considerablemente con el aumento de población, la creación de super-mercados en lugares alejados de las ciudades, el transporte consiguiente de mercancías...

Según estadísticas, el tráfico medio diario sobre la autopista de esta zona, en los últimos tres años, son las que figuran en el estado de la página siguiente.

Parece que se han superado todos los cálculos previstos, lo que queda explicado parcialmente por el uso de las autopistas en las "horas punta" y por la seguridad que encuentra el conductor en aquéllas, d o nde, igualmente, se siente más cortés y educado, y más consciente de su propia seguridad como consecuencia inmediata de la seguridad ajena. 


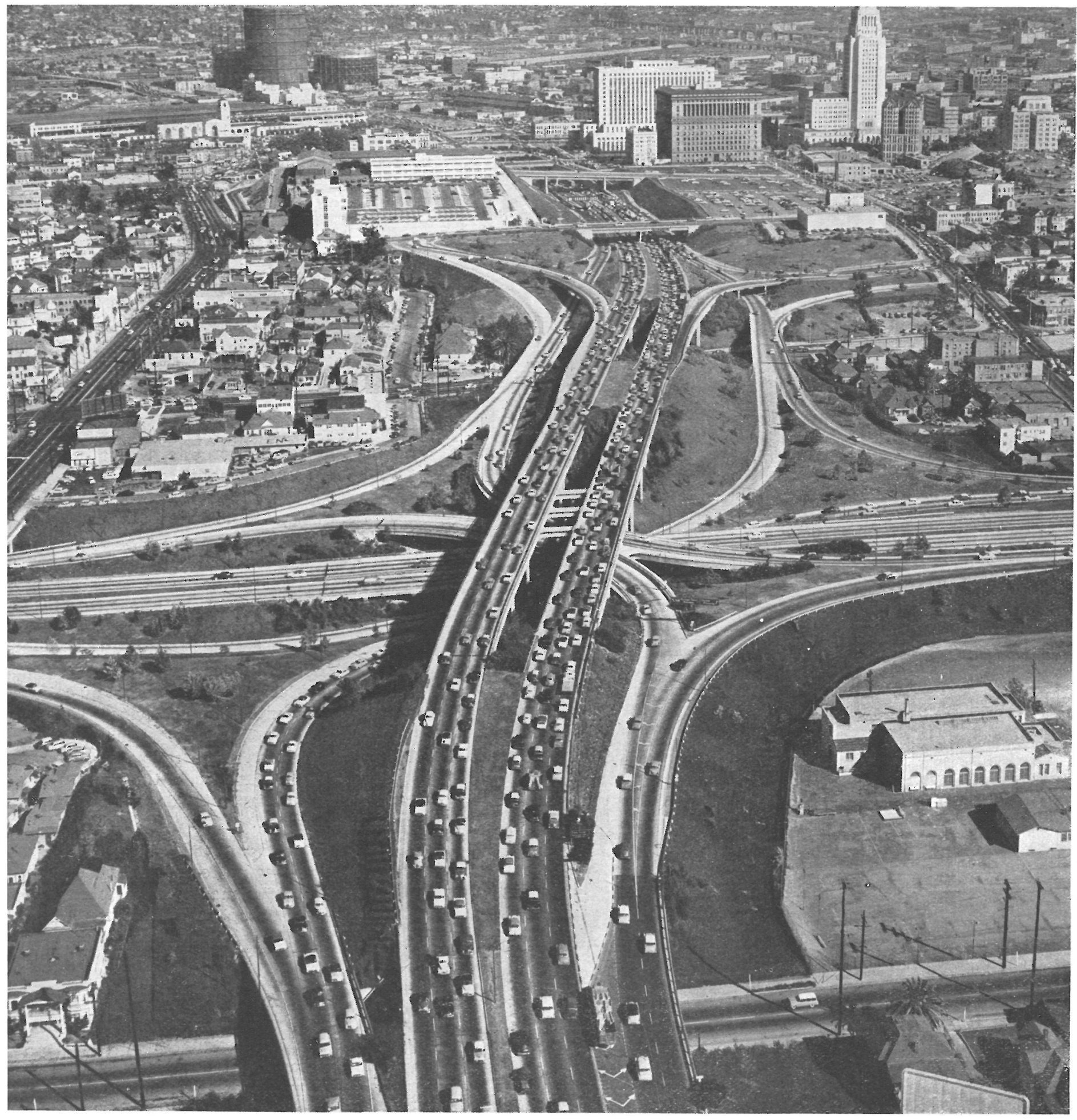

Tráfico medio diario

Autopista de Hollywood

Autopista de Pasadena

Autopista de Santa Ana

Autopista de Harbor

Autopista de Colorado ...

Autopista de Long Beach

Paso de cuatro niveles...
1954

1955

1956

$168.000 \quad 180.000 \quad 185.000$

$\begin{array}{lll}110.000 & 112.000 & 114.000\end{array}$

$\begin{array}{lll}90.000 & 113.000 & 145.000\end{array}$

$80.000 \quad 88.000 \quad 96.000$

$\begin{array}{rrr}125.000 & 160.000 & 175.000\end{array}$

$\begin{array}{lll}30.000 & 27.000 & 29.000\end{array}$

$\begin{array}{lll}10.000 & 31.000 & 37.000\end{array}$

$\begin{array}{rrr}242.000 & 280.000 & 300.000\end{array}$ 


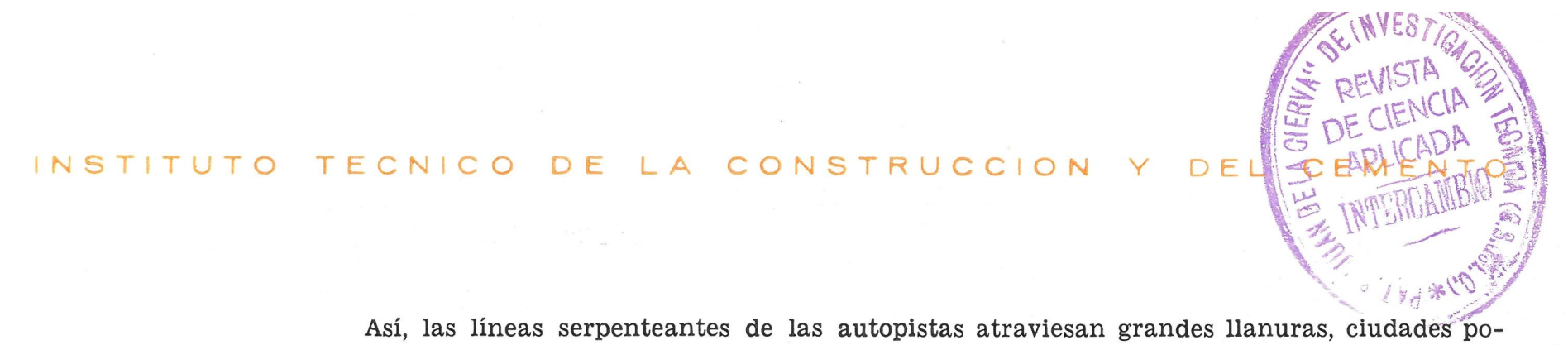

Asi, las lineas serpenteantes de las autopistas atraviesan grandes llanuras, ciudades pode "giros", "tréboles" y pasos elevados, complejos y variados, pero eficientes en la gran misión de resolver el tráfico rodado, creando para ello toda suerte de facilidades. La autopista corre, dividida en varias "calles" para distintas velocidades, acomodándose a las necesidades y gustos de los usuarios.

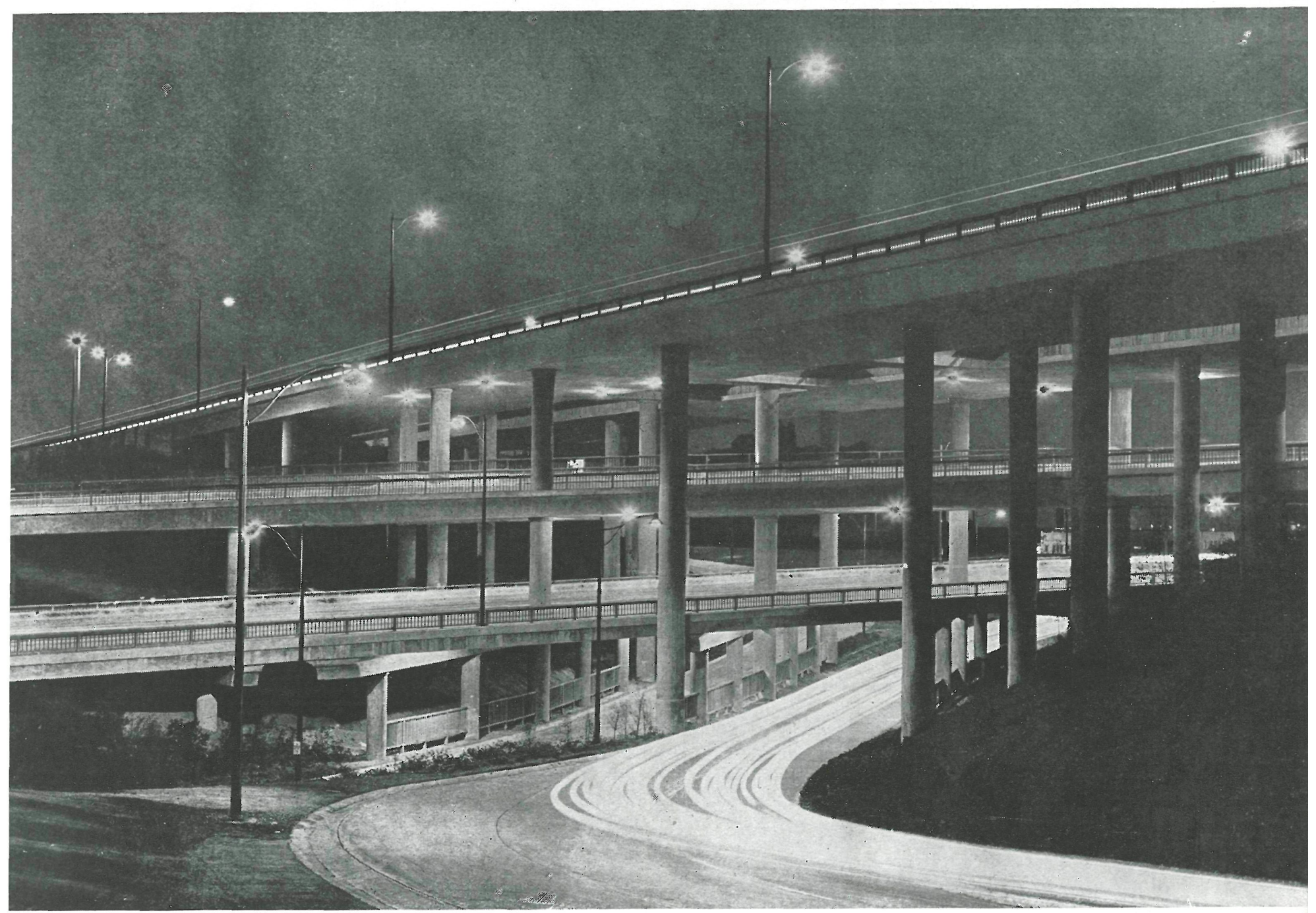

En esta misión importantísima colaboran el Estado, las empresas constructoras y el mismo conductor, poniendo todos a contribución una voluntad digna de encomio y un deseo muy interesante de servirse mutuamente. Bien podían servir de ejemplo estas directrices de un pueblo joven y animoso que marcha con pasos de gigante en el progreso y la civilización. 

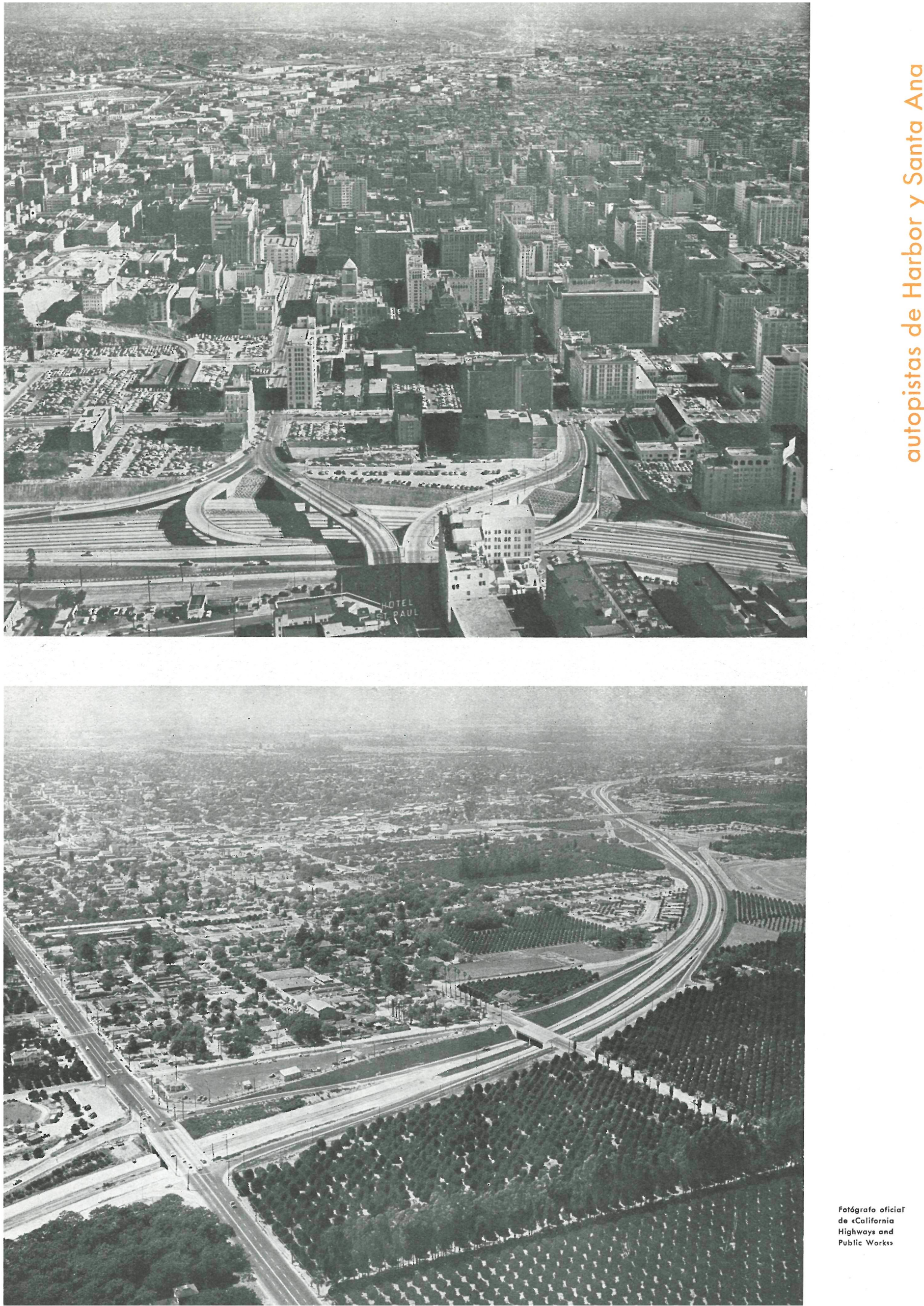

Fotógrafo oficial

de cCalifornio

Public Works 